\title{
Editorial
}

\section{Advanced Reactor Concepts and Fuel Cycle Technologies}

\author{
Hangbok Choi ${ }^{1}$ and Wei Shen ${ }^{2}$ \\ ${ }^{1}$ General Atomics, 3550 General Atomics Court, San Diego, CA 92121-1122, USA \\ ${ }^{2}$ Canadian Nuclear Safety Commission, 280 Slater Street, Ottawa, ON, Canada K1P 5S9 \\ Correspondence should be addressed to Hangbok Choi; h.choi@ga.com
}

Received 7 April 2013; Accepted 7 April 2013

Copyright (c) 2013 H. Choi and W. Shen. This is an open access article distributed under the Creative Commons Attribution License, which permits unrestricted use, distribution, and reproduction in any medium, provided the original work is properly cited.

Nuclear power is an abundant source with zero $\mathrm{CO}_{2}$ output, and expanded fission power is an attractive option especially in growing countries. Various reactor concepts are being studied to comply with requirements of future nuclear fuel cycle such as safety, sustainability, cost-effectiveness, and proliferation risk reduction. These generation IV reactor concepts include both thermal and fast reactors and are being developed in conjunction with advanced reprocessing technology. In addition, beyond-generation IV type reactors are being developed, which mitigate the concern on the nuclear waste issue by adopting very high-burnup fuel and long-life core. Considering movement towards future nuclear cycle, we have collected papers which cover the topical areas of new activities in advanced reactors and fuel cycle technologies and published these in this special issue on advanced reactor concepts and fuel cycle technologies.

This special issue contains 10 research articles, including seven papers on advanced reactor concepts. The advanced reactor concept covers sodium-cooled fast reactor (SFR), gascooled fast reactor (GFR), supercritical water reactor (SCWR), and pressurized water reactor (PWR). The research topics include an advanced Korean SFR system design and analysis, improvement of Japanese SFR core performance by moderators in the blanket region, use of moderating materials to compensate the drawback of minor actinide containing transmutation fuel in European fast reactors, a multiphysics modeling technique for in situ breeding and burning reactors, an ultralong fuel cycle compact GFR system design and analysis, a simulation strategy for the evaluation of neutronic properties of a Canadian SCWR fuel channel, and a thorium-plutonium fuel cycle for operating cycle extension of a PWR. The special issue also includes research results on the modeling forced-flow chemical vapor infiltration for fabrication of SiC-SiC composite materials, development of inactive demonstration facility for a proliferation-resistant pyroprocessing technology, and the economic analysis of a closed fuel cycle.

Hangbok Choi Wei Shen 


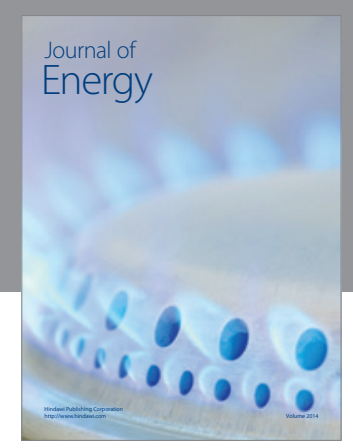

Journal of

Industrial Engineering
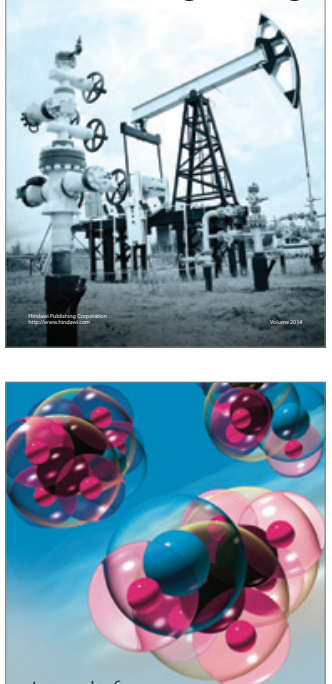

Fuels
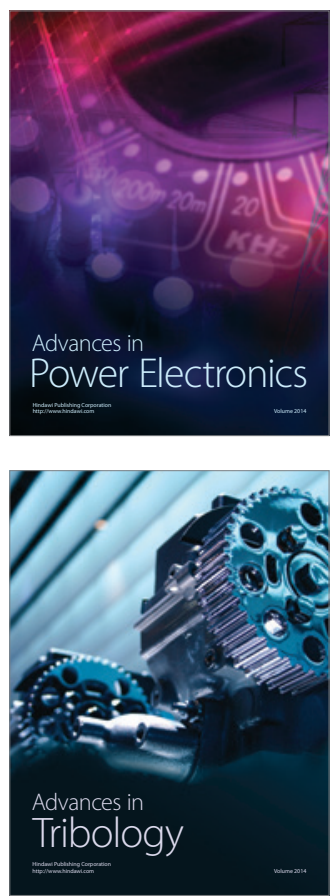

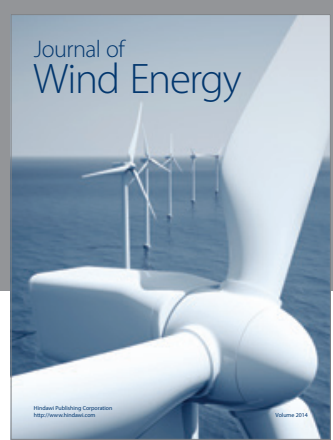

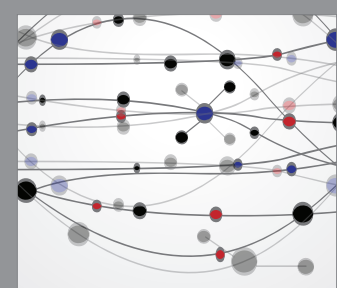

The Scientific World Journal

Submit your manuscripts at http://www.hindawi.com

Journal of

Structures
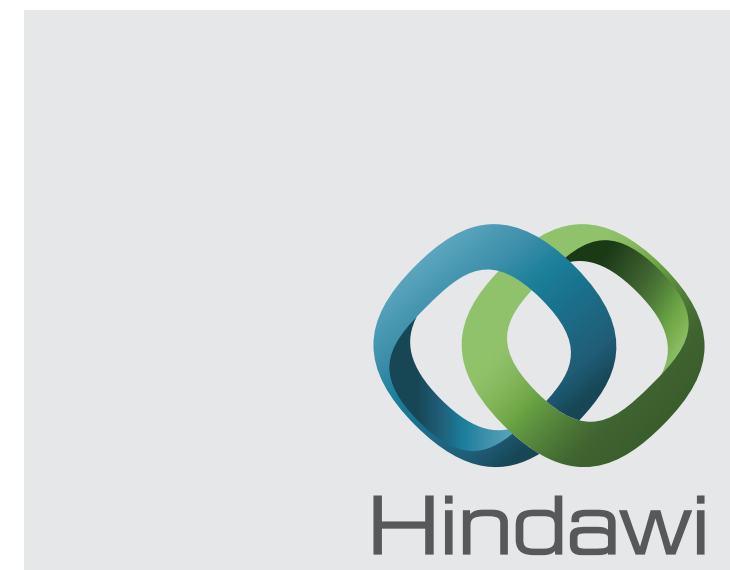

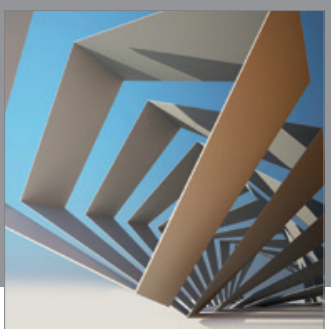

Rotating

Machinery
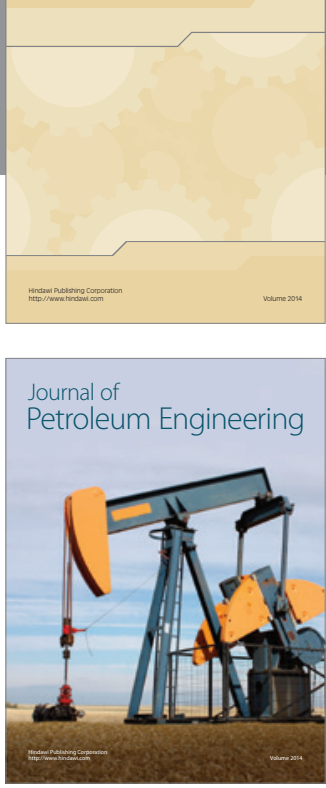

Journal of

Solar Energy
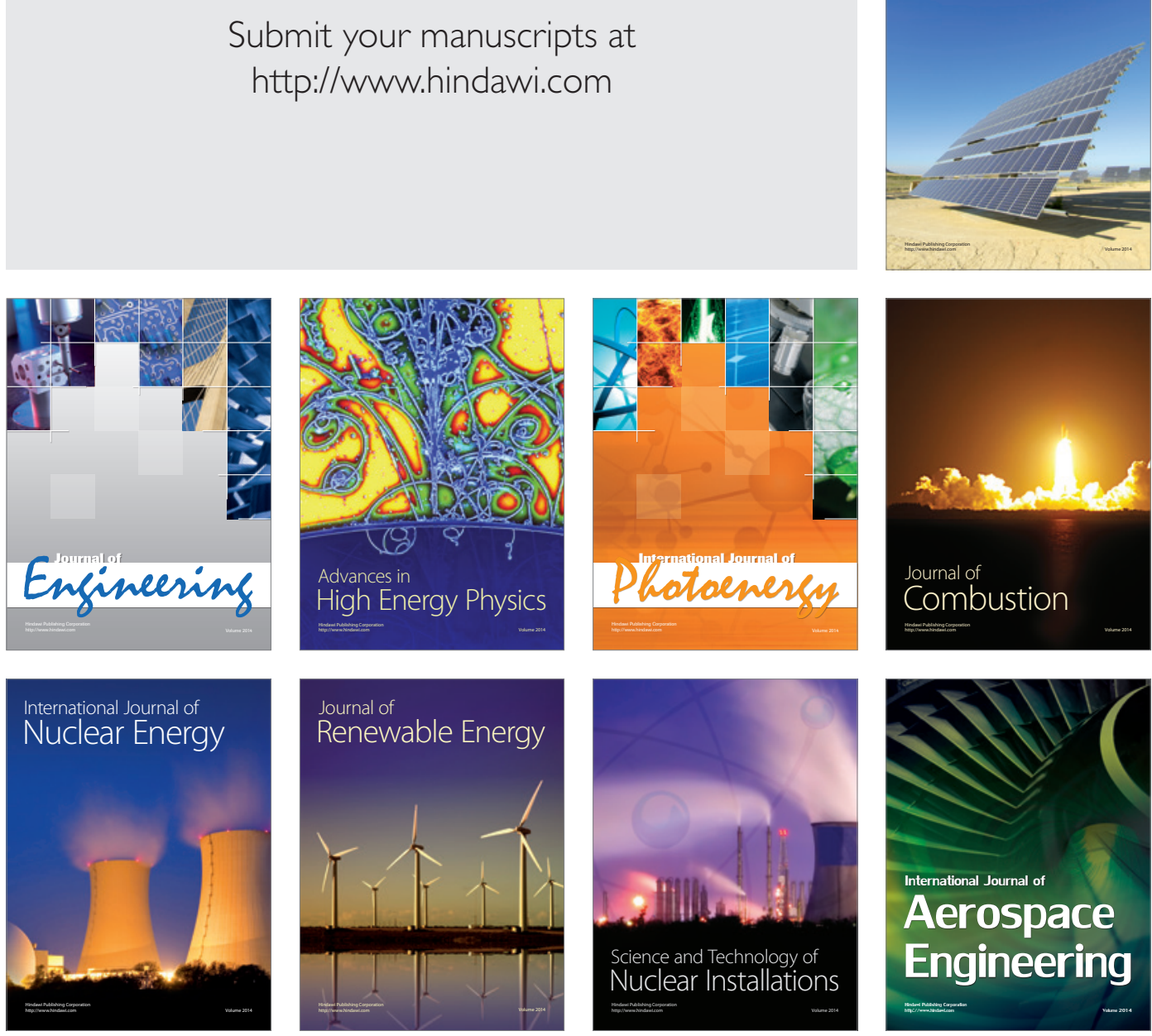